\title{
PARRA EN PRIMERA PERSONA
}

\section{Adán Méndez}

\begin{abstract}
A partir de múltiples entrevistas y conversaciones con Nicanor Parra, elaboradas por distintas personas y momentos, Adán Méndez organiza un diccionario de declaraciones en primera persona del centenario poeta.

Based on multiple interviews and conversations with Nicanor Parra, conducted by different people at different times, Adán Méndez organizes a dictionary of first-person statements of the century-old poet.
\end{abstract}

$\mathbf{P}$

arra dejó hace mucho tiempo de dar entrevistas, lo que es una pena porque sólo Borges lo empata como entrevistado. De entre los vivos, nadie es más inteligente y divertido. Mi opinión al respecto es que dejó de dar entrevistas debido a la fenomenal e inédita integración personal necesaria para lograr los Discursos de sobremesa, integración que ya no admite un poeta que escribe por un lado y que da entrevistas por otro. Debe haber otros motivos, pero éste es intrínseco.

Falta aún mucho trabajo de recopilación respecto de sus entrevistas y conversaciones, aunque en los tres libros aquí utilizados hay suficiente para conocer la voz personal del protagonista exclusivo de la antipoe-

AdÁn Méndez (Concepción, 1967). Poeta. Fundador y director de Ediciones Tácitas. Autor de Antología precipitada (1992), Visión de la poesía brasileña (1996, junto a Thiago de Mello), Te amo y te odio (2004, antología de la poesía erótica de Armando Uribe), Bar abierto (2005, antología de Hernán Miranda). Colaboró en la edición de las obras completas de Nicanor Parra. Email: mendez.adan@gmail.com 
sía, una de las grandes aventuras espirituales del siglo XX, y la que en mejor forma pasa al XXI.

Para reconocer la fuente de cada cita, agregué iniciales al final de cada extracto. Estas iniciales corresponden a los siguientes libros de conversaciones y entrevistas:

LM: Conversaciones con Nicanor Parra. Leonidas Morales. Santiago: Ediciones UDP, 2014. Ésta es una reedición del libro editado por Morales en 1990 (Santiago: Editorial Universitaria), con una conversación realizada en 1970 y otra entre los años 1989 y 1990.

MTC: Así habló Nicanor Parra en El Mercurio. María Teresa Cárdenas. Santiago: Ediciones Aguilar, 2012. Selección de entrevistas dadas por el poeta al diario El Mercurio entre los años 1968 y 2008.

RdC: Nicanor Parra: conversaciones de Chicago. René de Costa. Inédito. Conversación realizada entre Parra y el académico De Costa en 1987.

\section{ANGUITA, ANTOLOGÍA DE}

Había leído pequeñas cosas en una revista del internado, unos versos de Julio Barrenechea, que me llamaron la atención: "La señorita manos blancas / está vestida en bois de rose. / Por la ventana abierta al cielo / pasa una nube que se va". Cosas así, deliciosas, rococó, de refinamiento. Pero todavía no escribía, no hacía nada. Cuando un buen día aparece en mis manos la Antología de Anguita: Esto fue un despertar, un sacudón tremendo. Y dije, yo también puedo hacer estas cosas, jesto sí que lo puedo hacer! Y me largué a escribir de inmediato. Pedraza era amigo mío, y le dije: "Mira, eso escribí". "Formidable —me dijo-, esto es formidable. Se lo voy a llevar a Millas". Millas leyó: "Formidable". De la noche a la mañana quedé a la altura de Millas y de Pedraza. Formamos un trío. Quedé inmediatamente de poeta, y me invitaron a tomar cerveza y a caminar en la noche cuando tenían salida. Empecé a ver el mundo maravilloso en que vivían, en que se movían estos dos genios, y a sentirme igual a ellos. [LM]

\section{ANGUITA, EDUARDO}

Una vez nos encontramos frente a la librería Nascimento, cuando no estaba en la calle de la plaza, sino como dos cuadras hacia la cor- 
dillera. Lo vi mirando una vitrina, y me dije: "Ya, le llegó a Anguita porque ahora lo voy a pillar y voy a establecer un contacto con él". Me acerqué y me puse a mirar la vitrina también. Me miró, y me dijo: “¿Para dónde va usted, señor?”. Yo le contesté: "Voy en esta dirección”. Él respondió: "Yo voy en la contraria". Y se fue. [MTC]

\section{ANTIPOESÍA}

Creo que en último término es preferible ver a la antipoesía como un síntoma neurótico, eso es más auténtico que pensar a un señor que dice que va a escribir una poesía original e interesante. Eso a mí no me interesa. No, la antipoesía es algo que viene desde las plantas de los pies, es decir, es algo de vida o muerte. Detrás tiene que haber una articulación... de tipo físico, de tipo somático y psíquico. Esto no es posible inventarlo, esto es una cantidad de síntomas.

$[\ldots]$

Estas son consideraciones sumamente generales, la antipoesía no es un invento de nadie, en realidad, el propio Homero ya tiene su antipoeta. Homero, tal vez, es un poeta del yin o del yang, pero Arquíloco viene simultáneamente del yin y del yang. Quevedo también, por cierto, es simultáneamente poeta y antipoeta. Lo que pasa es que yo me apoyo en esta palabra, en cierta forma, y llamo la atención sobre un hecho que viene ocurriendo en la historia de la poesía desde que el mundo es mundo: hay ciertas formas de la poesía, las formas poéticas nacen, crecen y mueren; los movimientos nacen, crecen, mueren, y cuando están entonces por desaparecer, surge un nuevo planteamiento que es antipoético en relación con lo anterior. Yo creo que lo que he hecho no tiene otra importancia, no tiene otra trascendencia. Me hice cargo no más, en el momento histórico que a mí me ha tocado vivir, de algo que había que hacer, so riesgo de empantanamiento. Me parecía, por ejemplo, que ya no era posible seguir insistiendo en la fórmula nerudiana, en la musicalidad nasal y en los estertores del surrealismo; me parecía que había que recuperar un contacto con la vida real, que había que, además, recuperar la idea. Los modernistas confiaron demasiado en una sola dimensión del lenguaje: solamente en la parte fonética, y pusieron poca atención al significado. A mí me pareció que había que recuperar, para la poesía, no tan sólo el nivel del significado — sin perder el fonético—, sino también el sintáctico. Y la poesía que hago actualmente es ya más sintaxis que otra cosa. $[\mathrm{RdC}]$ 


\section{ANTIPOETA}

Los demás poetas nacían mayores de edad, del vientre materno ya salían mayores de edad, lo sabían todo, eran marxistas, leninistas, estalinistas, hochiministas, castristas, pinochetistas. En cambio, este personaje antipoeta es un alma en pena, anda buscando alguna manera plausible de hablar. Además, simultáneamente yo estuve durante cuatro años con la voz perdida, no podía hablar. Podía decir palabras aisladas: árbol, árabe, sombra, tinta china. Pero juntar las cosas no podía. Por ejemplo: podía yo decir "qué", "hora", "es”, pero "¿qué hora es?" no me podía salir. No podía hablar, no era una simple especulación. Y a medida que Poemas y antipoemas fue siendo aceptado por la crítica y por los lectores empecé a recuperar la capacidad de hablar, porque, claro, cuando los lectores aceptaron el libro, yo dije se puede hablar de esta manera, tengo derecho a hablar entonces. Parece que todo ha consistido en la búsqueda, no de un lenguaje poético, sino de una manera de hablar, para conversar y para comunicarse con los interlocutores. $[\mathrm{RdC}]$

\section{ARENAS, BRAULIO}

Braulio Arenas, en forma muy relativa nomás, me dio la bendición. Incluso una vez que se publicó el libro me hizo un chiste pesado en la calle. Ya se habían pronunciado Alone, Teófilo, Neruda, o sea, ya estaba establecido que éste era un libro importante. Me encuentro con Braulio en la calle y me dice algo así: "Nicanor, yo te voy a decir una cosa a ti, lo que eres en poesía, tú eres un buen poeta mexicano", y siguió andando. $[\mathrm{RdC}]$

Cuando con Enrique Lihn y Jodorowsky hacíamos el Quebrantahuesos y lo exhibíamos con gran éxito en las vitrinas del restaurante Naturista - lo que nos sitúa todavía más cerca del pop- descubrimos más de alguna vez a Braulio Arenas que estaba al otro lado de la calle con sus gafas negras espiando lo que estaba ocurriendo, porque él se sentía, me pareció a mí, directamente aludido. Y superado, creo yo, porque él no llevó nunca sus juegos a una culminación tan brutal como ésta, y al mismo tiempo ofendido, porque nosotros íbamos hacia un surrealismo estridente. El de él era un surrealismo poético y menor, de joyería. No, nosotros nos lanzábamos con todo el cuerpo. [LM] 


\section{ARTE}

La catarsis tiene que ver con recuperación de identidad, recuperación de salud. O sea, se escribe poesía — se dice tradicionalmentepara recuperar la salud o la identidad perdida. Hace mucho tiempo que se ha tenido una doctrina de esta naturaleza.

Y, claro, en algunos casos yo creo que es así, pero, fíjense ustedes que en la antipoesía en general es al revés, es una poesía juguetona. Y ¿quiénes juegan? Los enfermos no. Juegan los que tienen muy buena salud. Así que la antipoesía es un derroche de energía, es un derroche de salud. Es al revés: no es una catarsis, es una anti-catarsis. Pero cuando se piensa en el arte como mecanismo de autorregulación, tal vez se puede decir que la antipoesía cae en esta definición. Hay exceso de energía, entonces hay que perder, hay que liberarse del exceso de energía y de ahí salen los poemas. De ahí sale la obra de arte y así el sistema no explota. Porque si hay exceso de energía puede explotar también el sistema, si hay defecto de energía se puede congelar el sistema, se puede detener. Por eso me parece preferible definir o dar una aproximación al problema de qué es al arte en términos cibernéticos.

Es decir, que el arte es un mecanismo de autorregulación del espíritu del individuo o del espíritu de la comunidad también. Y en este caso, entonces estamos en paz con la pregunta de qué es la antipoesía. Porque la poesía lúdica no queda incluida en la teoría de la catarsis, no queda incluida para nada. [RdC]

\section{ARTEFACTOS}

Yo prefiero decir que un artefacto es una configuración lingüística autosuficiente, que se basta a sí misma. La palabra "autosuficiente" es una noción que viene de otros sectores del pensamiento, no está muy manoseada y no presupone un juicio de valor... Una configuración lingüística que tiene sus leyes propias, digamos, que se sostiene por sí misma. Una estructura lingüística en último término, primaria sí, muy elemental. La misma eficacia que tiene un aviso de un diario. A través de una configuración muy breve de palabras uno se pone en contacto con algo que está más allá. Por ejemplo, cuando se anuncia un departamento: a través de la configuración de palabras uno se puede imaginar ese departamento que necesita urgentemente. En el artefacto no es un 
departamento propiamente tal lo que se anuncia: es algo que el lector necesita, algo que anda buscando de una manera u otra. Una cosa parecida ocurre cuando se entra de noche a una ciudad moderna. Uno viene de la nada y los avisos luminosos como que lo llenan, como que de alguna manera lo hacen vibrar, lo hacen vivir, y uno va de un aviso a otro y cada aviso es una especie de pinchazo a la médula. Esta noción de pinchazo a la médula es interesante. Se trata de tocar puntos sensibles del lector con la punta de una aguja, de galvanizarlo de manera que el lector mueva un pie, mueva un dedo o gire la cabeza. Interesa mucho no perder de vista la relación de texto a objeto o a mundo que está más allá del texto mismo. El artefacto está apuntando a una realidad que existe con anterioridad al artefacto. Por ejemplo, cuando se lee el siguiente aviso: "Did you Mc Lean your teeth today?", estamos frente a un artefacto con toda la barba. Desde luego llama la atención: el que lo lee se concentra y en seguida se trata de que el sujeto no tan sólo piense en lo que se está diciendo, sino que vaya y compre un determinado tubo de pasta de dientes. Exactamente lo mismo pasa en el artefacto: hay que vender una mercadería, una mercadería que es de otra naturaleza y que al lector le es de gran utilidad para su vida. [LM]

\section{BELLEZA}

Enrique Lihn dice que la belleza es "ese ganso atravesado en la historia literaria". Bueno, yo prefiero simplemente modificar el concepto de belleza y recurrir a un truco platónico, y hacer coincidir la belleza con la necesidad, con la verdad. A pesar de que esta última palabra también es muy delicada. Pero si se la vuelve a redefinir, entonces la cosa marcharía. Claro que la belleza como un refinamiento de la forma evidentemente que es algo fuera de foco en este punto de vista. [LM]

\section{CEMENTERIO}

Bueno, tú sabes que el cementerio es para mí un tema favorito, tal vez por el hecho de que yo prácticamente me crié en un cementerio. En Chillán vivíamos a unos pocos metros del cementerio y era un lugar fundamental para todos los niños del barrio. Todo lo que ocurría a su alrededor, los funerales pomposos, con bandas de músicos que atrave- 
saban este suburbio misérrimo donde nosotros vivíamos, todo esto era una fuente de energía. Y además, nos íbamos a jugar también al cementerio. $[\mathrm{RdC}]$

\section{COLUMNISTAS}

La fluidez mía opera en el espacio de la realidad real, de la vida comunitaria. La aproximación mía última en un comienzo fue a la prosa. Prefería partir de la prosa antes de que de la poesía tradicional. Después fue el habla. Y ahora, en vez de partir de la prosa de la novela, por ejemplo, prefiero partir o prefiero acercarme y tener que ver con el periodismo.

En esta dirección debo decir que los escritores que me interesan más en este momento en Chile no son los poetas ni los novelistas, sino los periodistas. Los columnistas. Yo prefiero leer una columna de Pablo Huneeus antes de que leer un poema de cualquier poeta. Lo digo porque no hay ninguno aquí presente [risas]. Pero realmente es así, prefiero leer una buena columna antes de que un pretendido buen poema. En una época se dijo que Chile era un país de historiadores. Después se dijo que Chile era un país de gramáticos. Después, un país de poetas cuando aparecieron Neruda, Huidobro, Mistral. Ahora desaparecieron ellos y hay que decir que Chile es un país de columnistas. [RdC]

\section{CREACIÓN}

Personalmente, la palabra "creación" la he eliminado hace mucho tiempo de mi vocabulario. Me parece una palabra pomposa, mitológica y engañosa. Yo prefiero usar, en vez de la palabra "creación", la palabra "hacer". Prefiero escribir un libro que se llame Poemas prefabricados antes que escribir un libro que se llame Poemas creados. Hay que buscar más bien palabras indeterminadas, que no estén contaminadas por significaciones culturales ya manidas y en descomposición. [LM]

\section{DE ROKHA, PABLO}

Yo era un don nadie, estaba semirreclutado por Neruda, pero Pablo de Rokha trató de reclutarme a mí también, esto antes, cuando yo estaba en Chillán. Él pasó allí con sus libros y entonces yo lo acogí, fui 
útil para él, le hice una fiesta, le armé un recital, le ayudé a vender sus libros, le di nombres de personas que podían comprarle, porque era un poeta que yo admiraba y sigo admirando. Pero creyó entonces que había llegado el momento en que el neófito se incorporara a la secta y entonces me invitó abiertamente, me dijo que "eran muy pocos los privilegiados, muy pocos los elegidos y usted compañero, usted es uno de ellos, así que usted déme unos textos para publicarlos en Multitud". Entonces le dije sobre la marcha: "Yo le agradezco mucho Pablo su invitación, pero quiero decirle inmediatamente que yo no voy a poder aceptar su invitación, porque yo soy amigo suyo pero también soy amigo de Neruda, y en su revista se ataca a mi amigo, de manera que yo quedaría muy mal ante él y ante mí mismo si le aceptara esta invitación". Me dio una mirada horrenda y se cerró entonces para mí. Después vinieron las patadas y los ataques. Y no tan sólo una vez, varias veces. Pero el último contacto con De Rokha fue en un cementerio. Cuando se suicidó la Violeta. Ellos eran amigos, entonces él fue y me abrazó en público y me dijo algo así como: "Lo acompaño en su dolor, compañero". Hablaba así él. [RdC]

\section{DISCURSOS DE SOBREMESA}

Aparte de mis trabajos prácticos, parece que todo converge hacia los Discursos de sobremesa, un tipo de textos que parecen muy tontos, pero ¡cuidado! Hay planteamientos de profundidad ahí. Rimbaud nunca se hubiera interesado en algo así, ni Baudelaire tampoco. Son "voladas" individuales las suyas, son voladas modernistas. Y, en cambio, el Discursos de sobremesa es todo lo contrario de lo que pretenden esos "poetas malditos": acá, el modelo es más bien Juan Sebastián Bach, el artista integrado a la comunidad, no en contradicción con su medio. La clave modernista está en asustar al burgués; la clave del posmodernismo - Bach—, en seducirlo. Siempre he buscado más bien la simpatía del lector, no ahuyentarlo. Mal que mal, yo he sido un poeta popular, ¿no? [MTC]

\section{DUCHAMP, MARCEL}

Bueno, yo te pregunto lo siguiente: ¿no consideras tú que una de las grandes obras de este siglo y posiblemente la principal, la más importante de todas es la Mona Lisa con bigote de Marcel Duchamp? 
Aparentemente es una puerilidad, en el mal sentido de la palabra puerilidad. Pero cuando una broma funciona quiere decir que hay gato encerrado en ella. Si una broma te divierte a ti, te entretiene, puedes perfectamente escarbar detrás de esa broma y te vas a encontrar con algo, llamémoslo, importante.

Tú miras la Mona Lisa con los bigotes que le pintó y dices: "Esto es una broma, esto era una broma, me gustó mucho esta broma jajajá", pero le falta profundidad, le falta compromiso. Algo le falta para ser una obra arte en el sentido tradicional de la palabra: le falta seriedad, le falta dramatismo. Pero si te pones a trabajar sobre esta broma, puedes perfectamente seguir el siguiente camino, que es el camino que siguió realmente Marcel Duchamp y los dadaístas, y la justificación última del dadaísmo está dada incluso en la ciencia tradicional. ¿Cómo es posible que nosotros hayamos construido una cultura que desemboca en la Primera Guerra Mundial? ¿Es respetable, es considerable, es serio esto, en último término? Una cultura, una civilización que nos lleva fatalmente a la Primera Guerra Mundial... No puede ser serio.

Nosotros nos rebelamos contra toda esta cultura que conduce a la Primera Guerra Mundial y pescamos la expresión máxima de esta cultura — que es la Mona Lisa - y le pintamos bigotes. Eso es lo que se merece esta cultura. ¡Puta, que es dramático! ¡Por Dios que es importante esto! Me gustaría ver si los cuadros tradicionales que se las dan de serios llegan a un punto tan neurálgico como éste. Ésta es una crítica a toda la cultura occidental. ¡Caramba! ¡Dios Santo! [RdC]

\section{ECOLOGÍA}

Es como en un naufragio: ¿qué se saca ahí con decir que no fumen?, ¿que no griten muy fuerte? El naufragio sigue su curso. Lo que sí hay que hacer es concientizar a la gente para que tome nota del problema propiamente tal y que no piense que es un problema de orden municipal; que no se trata de barrer mejor las calles, de regar las plantas. Ésa es una pantalla, una de las maneras que tiene el propio sistema de defenderse. Voladores de luces para impresionar y para hacer creer que se está haciendo algo. Las soluciones tienen que encontrarse a nivel internacional. Ni siquiera los gobiernos individuales pueden tomar medidas efectivas. Por ejemplo, si el Presidente de Bolivia decidiera 
hacer una república ecológica no podría, porque la contaminación es internacional. La acción individual no conduce a nada, o conduce a muy poco. Es bienvenida, pero a condición de que no se piense que se está resolviendo el problema ecológico. [MTC]

\section{EROS}

El tipo ha sido herido muchas veces, está lleno de cicatrices en materia de relaciones eróticas: cada vez que se ha entregado, que ha abierto los brazos, usando una expresión chilena, ha "salido mote". Entonces ya duda de si entregarse o no y al final evoluciona hacia la no entrega definitiva. El tipo se cierra como ostra y no hay manera de capitalizarlo. Pero no renuncia el personaje a los beneficios y a los goces del amor. El tipo elude las molestias, las partes críticas del amor, pero él de todas maneras quiere probar el manjar y quiere forzarlo a fondo y hasta el infinito. O sea, se produce un desplazamiento del amor hacia la sensualidad. El personaje último es inclusive un personaje pornográfico. [LM]

\section{FARÁNDULA}

La farándula se sustenta en la siguiente frase: "A bailar, a bailar, que el mundo se va a acabar". Esto opera en el inconsciente colectivo. Después del colapso ecológico y la amenaza nuclear, quieren farrearse lo que les resta por devastar. No les importan las generaciones venideras. Más tarde vendrá la pornocultura y el basurarte. [MTC]

\section{GATO EN EL CAMINO}

De repente Millas me hizo un parelé. Yo escribí una cosa que es "Gato en el camino", un cuento, un anticuento, el año 35, y de la nada, absolutamente de la nada. Yo digo: "Esta es mi colaboración para la Revista Nueva". Millas lo lee. "No — dice-, esto no sirve. Tú te quieres reír de la revista. Tú tienes que escribir algo serio". Yo ya estaba bastante sinvergüenzón: "Qué seriedad, de qué seriedad me hablas, ¿de las filosofías tuyas? Esas son pamplinas. Olvídate de tus filosofías". Millas empezó a sentirse cada vez más herido, y me expulsó de la revista: "No tan sólo no se publica 'Gato en el camino', sino que tampoco se publi- 
can las 'Sensaciones"'. "Muy bien — le dije-, vamos a ver si no se van a publicar". Me fui a hablar con Pedraza. "Qué te parece — le dije-, léete este cuento". "Esto es una maravilla —me dijo-, una maravilla. Vamos a hablar con Millas". Pedraza era muy lento y muy calmado. "Oye, Millas — le dice-, estuve leyendo el cuento de Parra, 'Gato en el camino'. Es un cuento sensacional, un trabajo macanudo". "Qué va a ser un trabajo macanudo", le dice Millas. En mi presencia todo esto. "Así es que no se publica", le dice Pedraza. "No, no se publica". "Entonces yo retiro mis dibujos, no se publican mis dibujos". "No se publican los dibujos, muy bien". Nos fuimos e hicimos una alianza indestructible con Pedraza. Lo primero que me dijo: "Ya es tiempo de que te diga cómo son las cosas realmente. Tú eres más poeta que Millas, no te olvides, eres más poeta que Millas". Yo me sentí pero lanzado al séptimo cielo. [LM]

\section{HOMBRE NUEVO}

El socialismo requiere de un hombre nuevo. No de un hombre como hoy lo conocemos, sino que de otro personaje. La misma crítica se le hace al cristianismo, evidentemente. El cristianismo también requiere de un hombre nuevo. La sociedad empírica de que yo hablo, es una sociedad que está más al fondo del cristianismo y más al fondo del marxismo también. Está más conectada con la animalidad, diría yo primaria, que con la racionalidad cristiana y con la racionalidad marxista. [LM]

\section{LENGUA LOCAL}

Ahora no tengo ningún problema en usar palabras, incluso, que tienen sentido solamente en el seno de una familia. Yo tengo algunos textos que solamente los puede entender un subconjunto formado por dos personas, que son los dos hijos míos últimos: el Barraquito y la Colombina. Entre los tres, nosotros nomás podemos entender eso. Pero si alguien por curiosidad quiere meterse ahí, puede hacer un esfuerzo y ver si se interesa o no. A ese límite llego yo ahora en principio. Recuerdo que alguien decía que había que escribir en inglés, porque el inglés es un idioma universal [risas]. No, no, escriba en el idioma que conozca bien. [RdC] 


\section{LIHN Y JODOROWSKY}

Solamente cuando empecé a poner en tela de juicio los dogmas de Neruda y de esa generación de García Lorca, etcétera, solamente en ese momento empecé a captar la atención de las nuevas generaciones. Enrique Lihn, por ejemplo, hizo un estudio del "Soliloquio del individuo" ahí por el año 1951, 52, un estudio que le dio para una conferencia completa que él leyó en el Instituto Chileno Norteamericano de Cultura y que después se publicó en los Anales de la Universidad de Chile. Jodorowsky es también muy importante en ese grupo. Con esta gente inventamos el Quebrantahuesos, que era una especie de diario mural hecho a base de recortes de diario. Pero éste no es un juego estrictamente surrealista. Tal vez en su apariencia exterior sí, porque los surrealistas juntaban, claro, una mitad de una frase con la mitad de otra, pero ellos buscaban efectos poéticos, insólitos, y nosotros no. Por lo menos yo buscaba efectos que podrían llamarse de grueso calibre. Yo estoy seguro de que en ese tiempo nosotros en Chile inventamos el pop... Componíamos estos textos a base de titulares de prensa, los más grandotes, más gordos, espectaculares. Los componíamos prácticamente de acuerdo con las normas de los collages, del pop, y agregábamos ilustraciones insólitas. Por ejemplo, hay un texto que alguna vez va a haber que fotografiarlo y que dice lo siguiente: "Muchas felicidades", con unas letras muy rococós y como con vidriecitos, así, que relumbran, tomadas de una tarjeta postal, y arriba de todo esto hay un gran corazón canceroso, lleno de grasa, cortado de una revista médica, y encima del corazón un par de noviecitos chicos recortados de El Mercurio, muy esquemáticos estos noviecitos. Bueno, tú ves que simplemente es una obra pop por donde se la mire. Textos semejantes hay un sinnúmero. [LM]

\section{MADRE}

La mamá [Clara Sandoval] lingüísticamente era muy poderosa. Prácticamente el lenguaje de El Cristo de Elqui es el lenguaje de ella. Muy realista, muy directo, que ella trajo del campo a los suburbios de Chillán y que enriqueció con los aportes del papá, un normalista de escuela, que manejaba un grado cultural distinto. Además, de la mamá cuenta mucho su temperamento, su voluntad. Ella le dio un grado al grupo familiar, aportó una fuerza centrípeta poderosa. [MTC] 


\section{MISTRAL, GABRIELA}

Yo no me rebelé nunca con la Mistral y mi admiración por ella todavía es total. Claro, porque ella se instaló en una especie de nicho de mármol, invulnerable, y además no pasa por ahí la historia de las vanguardias, no pasa para nada. Ella es una poeta intemporal en cierta forma, y no es polémica esa poesía. [RdC]

\section{MUERTE}

La idea que tengo ahora de la muerte es la que obtengo del taoísmo. Muerte y vida son nociones que operan en el valle de los opuestos. Pero resulta que eso no corresponde a una objetividad. Nosotros hemos sido degradados: perdimos nuestra unidad espiritual. En el espíritu unitario no hay vida ni muerte; hay Tao. Y ése es el camino del monje taoísta. Si se le pregunta: “¿Usted está preparado para morir?”, la respuesta correcta parece que es la siguiente: "Sí. Pero también para seguir viviendo". [MTC]

\section{LA NEGRA ESTER}

He estado pensando en relación con Roberto y La Negra Ester: hoy se dice que el teatro chileno se divide en dos partes, antes y después de La Negra Ester. Y la única respuesta es la siguiente: Roberto escribe en idioma patrio. En cambio, yo no. Yo perdí mi idioma patrio, mi idioma chillanejo. Tuve que aprender otro idioma al llegar al internado, y otro al entrar a la universidad. Y así sucesivamente. El idioma se va debilitando, hasta que se habla el idioma patrio con acento. Roberto no ha leído más de tres libros y ahí está su fuerza: El Quijote, El Lazarillo y Martín Fierro. Ahora pienso regalarle La Celestina, por el lenguaje teatral.

$[\ldots]$

Las décimas de Roberto son la materia prima, él ve las cosas así. Pero hay que distinguir dos aspectos. El mundo al que se refiere en sus décimas, que me parece un mundo magníficamente trasladado de la realidad a las palabras. Y por otra parte está el espectáculo de Andrés Pérez, que encuentro estupendo, pero que es distinto. Si hubiera trabajado a fondo en el plano realista, habría ganado en ciento por ciento. 
Yo personalmente pertenezco a una época en que el prostíbulo era una institución fundamental en la comunidad, y la cosa no era de ninguna manera tan pintoresca como aparece allí. Era de colores más oscuros. El mundo de Roberto es más fuerte. No estoy de acuerdo tampoco con la dimensión sicalíptica de la totalidad del espectáculo, eso no ocurría ordinariamente. [MTC]

\section{NERUDA, PABLO}

No sería posible yo como poeta sin el antecedente de Neruda. Creo que no pasa un día sin que piense en él siete veces.

$[\ldots]$

También hay que hacerle justicia a Neruda en otro plano, en su calidad de Sherlock Holmes. Una vez íbamos a su casa en Isla Negra, decididos a leer poesía todo el fin de semana, acompañados de un poeta venezolano. Pasamos a hacer un aro en Melipilla. Y esa noche, frente a la chimenea en Isla Negra, creo que ahí había unas damas de la localidad que visitaban en ese tiempo a Pablito. Se trataba de hacer una lectura de poemas. Cuando me tocó el turno a mí, yo no pude leer nada porque se había perdido la maleta, una maleta de suela café, de la Talabartería Inglesa, con todos los antipoemas, absolutamente con todos, y eran los únicos manuscritos que tenía. Entonces yo caí en un estado de coma. Esto pasó antes del viaje a Inglaterra. Y él los encontró. Bueno, a través de él. Yo no supe cómo lo hizo. El asunto es que al día siguiente, o tal vez esa misma noche, después de unas dos o tres horas, entró al living y dijo: "Aquí vamos a hacer un acto de magia". Vino con una manta, y esta manta lo cubría de la cintura hacia abajo. Se veía que había algo entre la manta y él. Dijo unas palabras medio misteriosas, y de repente de debajo de la manta sacó la maleta con los poemas. Él entonces es responsable de que hayan aparecido los antipoemas y de que se hayan publicado alguna vez. La maleta se había quedado en Melipilla y un chofer de una de las micros la trajo y la entregó. Eso es inaudito, porque el maletín era de buena clase. [LM]

\section{ORDEN DE LOS POEMAS}

El orden en que yo publico los poemas es el orden en que fueron escritos. O sea, después de escribir un poema siento la necesidad de 
hacer otra cosa, incluso de entrar en contradicción con él, con lo que se ha dicho anteriormente, con el estado de ánimo anterior, con el espíritu del poema anterior. Los libros están armados de acuerdo con un criterio cronológico, no con criterio estético. [RdC]

\section{PARRA, VIOLETA}

Con la Violeta teníamos una comunicación total, de vasos comunicantes. Con el tiempo llegó a ser inalámbrica, al estilo de los campos morfogenéticos de la inconciencia. Pero ella era mucho más liberada que yo, en el sentido de que a mí me interesaban y me siguen interesando las apariencias. No me atrevo a hacer lo que quiero. Creo que tengo deberes con la comunidad, que hay ciertos requisitos que hay que estar todo el tiempo satisfaciendo. [MTC]

\section{"PINGÜINOS"}

Los pingüinos de hoy ya no la llevan: la llevaban. Se ha reproducido en ellos el molde de los adultos, se han dividido. Quisieron llegar a las ideas generales, sistemáticas, y se los tragó el logos, la dialéctica. Debieron creerles más a los sofistas que a la racionalidad helénica. [MTC]

\section{POESÍA SOCIAL}

Yo sostengo lo siguiente, y aquí sí me voy a poner un poco pesado o más pesado todavía: la poesía social está por inventarse. Neruda no hizo poesía social. Trató de hacer una poesía social, pero ésa es una poesía estética, llena de alusiones literarias, con emociones sociales, pero sin pensamiento social. Creo que quien avanzó mucho en la dirección de la poesía social es Cardenal. Está mucho más adelante que Neruda en madurez filosófica. Yo aspiro a ser poeta social, eso es lo que quiero ser ahora. [RdC]

\section{EL QUEBRANTAHUESOS}

Alejandro Jodorowsky era el alma del Quebrantahuesos. En ese mismo tiempo yo era subdirector de la Escuela de Ingeniería, y por allá 
se aparecían Enrique Lihn y Alejandro Jodorowsky, que me iban a ver. Ahí planeamos el Quebrantahuesos. No hallábamos qué nombre ponerle, y no sé de dónde demonios saqué yo este "quebrantahuesos". Creo que el quebrantahuesos es un pájaro, después determinamos que en un libro de Pierre Macorland ataca a la marinería en la cubierta de un barco, y con el pico aparece cortando cabezas y columnas vertebrales. Es un pájaro de la pajarería chilena, una especie de cernícalo. La cuestión era quebrar huesos. La idea de no dejar títere con cabeza se repite, porque aquí mismo tengo un artefacto con títeres: "Si yo fuera Presidente de Chile no dejaría títere con cabeza / Comenzaría por declararle la guerra a Bolivia / Acto seguido me dispararía un tiro en la sien”. [LM]

\section{SERMONES Y PRÉDICAS DEL CRISTO DE ELQUI}

Lo que ha pasado con la literatura hispanoamericana, ustedes saben muy bien, es que al comienzo los chilenos trataban de hablar como hablaban los españoles. Después, abajo los españoles y entonces había que hablar o escribir como escribían los franceses, el modernismo. Después nos aburrimos de eso y entonces no, hablemos como habla Maiakovski, la poesía social, hablemos como se habla en Moscú. Y después no, hablemos como se habla en Londres, hablemos como habla T.S. Eliot, o como se habla en Nueva York, como habla Ezra Pound.

Bueno, ¿y cuándo vamos a hablar como hablamos nosotros mismos? Ahí el Cristo de Elqui da la solución. Esto es made in Chile. Aquí se asume la precariedad del lenguaje y de la vida chilena, nada de mundos artificiales, nada de escapismos, nada de orientalismos modernistas. [RdC]

\section{SOCIALISMO Y CAPITALISMO}

Si uno mira las cosas desde el balcón ecológico, entonces se ve simplemente que capitalismo y socialismo son dos hermanos gemelos, que están unidos por la espalda además, en el sentido de que los dos andan buscando lo que se llama el paraíso en la Tierra. Y para ambos el paraíso en la Tierra consiste en un sistema de artefactos. La tecnología es la herramienta común y básica para estos dos hermanos siameses. Y resulta entonces que en la práctica los ángeles socialistas han resultado tan fumadores como los demonios capitalistas. Y a estas alturas pode- 
mos decir que son igualmente depredadores. Los crímenes ecológicos del socialismo son tan graves o más que los propios crímenes del capitalismo. De manera que, desde este ángulo, ellos aparecen como la cara y la cruz de una moneda no más. Una misma moneda. [LM]

\section{VERSOS DE SALÓN}

Recuerdo que cuando yo escribí este libro trabajaba mucho con el concepto de que la poesía tiene que ser flaca, en oposición a la poesía gorda. Tiene que ser dura, en oposición a las blanduras nerudianas, tiene que ser dura y tiene que ser transparente. [RdC]

\section{VERSOS SUELTOS}

Una vez me hicieron esa pregunta en Nueva York, la gente de la revista Stony Brook, y salía allí una frase que es una especie de artefacto que explica la naturaleza del artefacto: "Los artefactos resultan de la explosión del antipoema". En la Antología de Jorge Elliott, del año 57, viene un poema que se llama "Versos sueltos", donde yo intercalo varios textos que son como avisos: "Se reparte jamón a domicilio", "véndese crucifijo de ocasión". Ahí están ya los artefactos, pero todavía no se ha producido la explosión del poema. Bueno, los artefactos son más bien como los fragmentos de una granada. La granada no se lanza entera contra la muchedumbre. Primero tiene que explotar: los fragmentos salen disparados a altas velocidades, o sea, están dotados de una gran cantidad de energía y pueden atravesar entonces la capa exterior del lector. Porque se trata de penetrar, de romper, de sacar al lector de su modorra y pincharlo. [LM]

\section{REVOLUCIÓN SEXUAL}

Sí, hay puntos comunes con los yippies, pero nuestros movimientos juveniles políticos son marxistas leninistas estrictos. La primera condición para ser yippie es estar decidido a todo, la vida individual es lo de menos. Ellos han puesto en jaque dos o tres veces al Pentágono y a la Casa Blanca. Su idea principal es poner en ridículo a la autoridad. Según ellos, la revolución se hace cantando, bailando, fumando mari- 
huana y "dando de patadas en los testículos a los pacos". Los jóvenes nuestros no piensan así. No estoy contra ellos. Me los explico y pienso que la revolución debe hacerse a través de la colaboración de los distintos grupos revolucionarios. Para decirlo más groseramente: los revolucionarios marxistas aparecen como revolucionarios del estómago (muy necesario por cierto), pero no debemos olvidar la revolución de la cabeza ni la revolución sexual.

Soy un tipo de 55 años y no creo tener acceso a la revolución sexual chilena, pero sobre la revolución de la cabeza no tengo la menor duda de que estamos atrasados. Yo estoy en ella desde que tengo uso de razón. Sé que hay tierra propicia porque el chileno por naturaleza tiene sentido del humor, que es lo único que no se puede no tener. El lema de la revolución yippie es: se terminaron las caras largas. [MTC]

\section{WHITMAN, WALT}

Me llamó mucho la atención el lenguaje que en inglés se llama "relaxed", un lenguaje más o menos suelto. Ésa es una poesía abierta: no hay métrica estricta ni un lenguaje poético convencional. Los poemas son como poemas-estudios, y no poemitas líricos. La descripción tiene una gran importancia en la poesía de Whitman. Incluso hay narraciones, pequeñas historias que intercala en su obra Hojas de hierba. El oficio de Whitman, la gran cantidad de materiales y la soltura con que los trabaja, y una cierta vehemencia pasional con que se aproxima a ciertos temas, creo yo que fueron las líneas de desarrollo de su poesía que más me tocaron. Al extremo de que consideré que todo mi trabajo anterior estaba fuera de foco, y no escribí más romancitos tipo Cancionero sin nombre. Traté de aprender la jerga whitmaniana y escribí un sinnúmero de poemas bajo la influencia de Whitman. Pero resulta una cosa cómica: que mientras trataba yo de hacer esas imitaciones, esos ejercicios whitmanianos, algo fallaba por la base. Los poemas de Whitman eran poemas wagnerianos, y yo podía pescar a ratos esa onda, pero después como que se producían algunas pifias: los personajes empezaban a deshacerse y el héroe se transformaba imperceptiblemente en un antihéroe. Esto me causaba a mí en un comienzo una gran desazón, porque no podía yo estructurar un personaje heroico. Yo quería eso, pero resultaba que mi vocación era otra. Solamente cuando me di cuenta de las 
limitaciones de Whitman, algo que vi perfectamente a través de Kafka y tal vez de otros humoristas, solamente en ese momento me di cuenta de que lo que podía haber de valioso en esos ejercicios era precisamente un personaje que pugnaba por entrar al poema, que era el antihéroe, y lo demás, esos acordes wagnerianos, estaba perfectamente fuera de foco. Cuando entendí que la cosa iba por ese lado, que el antihéroe tenía perfecto derecho a existir, de la noche a la mañana escribí un poema como "La víbora". Ese fue realmente el primero de los poemas poswhitmanianos. [LM] EP 